\title{
Migraine headache facilitators in a population of Polish women and their association with migraine occurrence - preliminary results
}

\author{
Piotr Chądzyński ${ }^{1}$, Aleksandra Kacprzak ${ }^{1}$, Wojciech Domitrz ${ }^{2}$, Izabela Domitrz \\ ${ }^{1}$ Department of Neurology, 2nd Faculty of Medicine, Medical University of Warsaw, Warsaw, Poland \\ ${ }^{2}$ Faculty of Mathematics and Information Science, Warsaw University of Technology, Warsaw, Poland
}

\begin{abstract}
Aim of the study. The occurrence of migraine is linked with some common lifestyle activities and conditions preceding the attack. Our study presents known and presumptive lifestyle factors and activities related to migraine, and compares them to the frequency of headache attacks.

Material and methods. 40 female patients of the Headache Outpatient Clinic in Warsaw, Poland, diagnosed with migraine, mean age 44.6 years, and 40 female participants from the control group, mean age 39.5 years, were included in the study. The study employed questionnaires reporting the presence of lifestyle factors and socioeconomic predispositions as well as the Migraine Disability Assessment Test (MIDAS) as data collection methods.

Results. Correlations between some of the lifestyle factors and the frequency of migraines occurred statistically significantly.

Conclusions. Some factors and lifestyle activities such as stress, relaxation, specific dietary products, fasting, fatigue, bright light, noise, weather changes or menstruation may have an influence on migraine frequency and severity in female patients, which can have an impact on migraine prevention.
\end{abstract}

Key words: migraine, trigger factors, lifestyle, headaches

(Neurol Neurochir Pol 2019; 53 (5): 377-383)

\section{Introduction}

Migraine is a common health problem occurring in up to $12 \%$ of the Caucasian population. According to epidemiological studies in Poland, the cause of about $49 \%$ of chronic daily headaches $(\mathrm{CDH})$ is chronic migraine [1]. The prevalence of migraine is up to three times more frequent among women depending on populations, and varies by age, with its peak between the ages of 35 and 45 , regardless of sex [2,3]. Stępień et al. determined the prevalence of migraine in the Polish population to be about $10 \%$. Based on their study, $75 \%$ of Polish migraineurs were female and migraine was more common in patients over 40 years old (72\%) [4]. Low household income and lower educational level can further increase migraine prevalence, significantly among women $[5,6]$. Migraine can have a major impact on the patient's quality of life, affecting it directly and causing complications such as functional disability or depression $[2,7,8]$.

Peroutka tried to identify the top ten migraine factors based on an analysis of 25 publications, of which stress was predominant [9]. Between $50 \%$ and $80 \%$ of migraine patients associated stress with headaches $[9,10]$. Other frequently mentioned factors include sleep disturbance and dietary factors like hunger, skipping meals, alcohol intake (especially red wine and beer), caffeine, chocolate and cheese, fatigue and weather changes $[9,11,12,13]$. Physical activity can further worsen the severity of headaches induced by alcohol intake [14]. Sleep and stress can play a greater role for patients suffering from migraine with aura, as opposed to environmental factors which may be more crucial to migraine patients without aura

Address for correspondence: Aleksandra Kacprzak, Department of Neurology, 2nd Faculty of Medicine, Medical University of Warsaw, 01-809 Warsaw, 80 Cegłowska Str., Poland, e-mail: olak1991@02.pl 
[10]. Another Polish study focused on the potential impact of body mass index (BMI) and serum lipid levels on increasing the risk of migraine [15].

Determining headache trigger factors among migraine patients could possibly help improve prevention in this group. Due to insufficient data in the Polish population, our present study was conducted to analyse the association between migraine and factors which are known to trigger, or are presumed to trigger, migraine headaches such as marital status, educational level, alcohol intake, sleep deprivation, dietary problems, stress, weather changes, exposure to flashing lights or a high noise level, staying at a high altitude, drug administration, menstruation, or working out.

\section{Material and methods}

We retrospectively evaluated the clinical data of 40 randomly selected female patients with a mean age $( \pm$ SD) of $44.62 \pm 10.64$ years (range 21 to 66 ) diagnosed with episodic or chronic migraine with or without aura, based on the criteria of the International Headache Society [14]. Our control group consisted of 40 women with chronic tension type headaches (TTH) diagnosed according to the International Classification of Headache Disorders $3^{\text {rd }}$ edition (ICHD-3) [14], with a mean age ( \pm SD) of $39.5 \pm 15.59$ years (range 23 to 76 years). This group was adjusted to the age and gender of the study group. All individuals in our study groups (the control-TTH group and the migraine group) were Caucasians. The mean age for the study groups was not significantly different (Wald-Wolfowitz runs test $-\mathrm{Z}=-1.350 ; \mathrm{p}=0.177$ ). The consecutively incoming migraine patients were examined in the Headache Outpatient Clinic from November 2015 to February 2017. A basic neurological and general examination was performed during planned appointments in the Clinic. Depending on individual needs, the patients were receiving either prophylactic or acute treatment. During our study, there were only a few male patients, so we excluded them from the study to avoid selection bias,deciding to pay attention only to the unified female patients group and the control group. Our study group did not omit individuals in migraine preventive treatment or those receiving medication for chronic migraine. We also did not select patients for the study on the basis of the onset of migraine or its duration.

All the patients completed a questionnaire that was created for the researchers' own use. Each set of questions was asked directly by the researchers, not over the telephone, after the confirmation of the migraine diagnosis and the examination of physical condition. All the patients agreed to their data included in the questionnaire being used for our study.

The questionnaire was divided into three parts. In the first, socioeconomic, part we assessed educational level, type of work (physical or mental), marital status and number of children. In the second part, each patient was asked about the concomitance of headaches and the following aspects of life: a stressful situation (e.g. exams, work interviews), relaxation after stress, the intake of dietary products such as chocolate, dairy, cocoa, seasonings, citrus, as well as alcohol intake, fasting, sleep deficiency or excess, workout/fatigue, exposure to bright or pulsing light, high levels of noise, staying at high altitude (e.g. in the mountains), sudden weather changes, medicine intake, and menstruation. We also asked patients if there were any other factors that they had linked with their headaches. In the final part, the Migraine Disability Assessment Test (MIDAS) [16] was used as a means to estimate patients' migraine severity and daily activity impairment. We compared triggers of headache in the migraine and in the TTH group. The complete questionnaire is set out in Table 1.

\section{Statistical analysis}

Non-parametric Wald-Wolfowitz runs test was performed for the group comparison. Null hypothesis was that the groups were independent and identically distributed, which was proved correct (p-value 0.177).

The presumptive headache trigger factors were presented as numerical variables and were analysed with chi-square tests such as Pearson's Chi-square test, Yates Chi-square test, and $\mathrm{V}$-square test. The null hypothesis in this case, and for all the subsequent tests, was that a statistical correlation between the headache occurrence in the patients' group and the trigger factors existed, while the alternative hypothesis was that there was no correlation. Pearson correlation coefficients were calculated to determine if a correlation existed between the frequency of headaches and the trigger factors we had taken into account in our study, in both the migraine and the control group.

The level of statistical significance was set at a p-value $<0.05$.

\section{Results}

According to the MIDAS, we categorised patients due to their migraine severity as Grade I, II, III or IV, which amounted respectively to $10 \%, 10 \%, 22.5 \%$ and $57.5 \%$ of the patients. 34 patients (85\%) were diagnosed as patients with migraine without aura, and only two patients (5\%) had attacks of migraine with aura. Four patients (10\%) had chronic migraine. The demographic and clinical data of patients is set out in Table 2 and Table 3 respectively.

There were non-uniform sample sizes in terms of educational level, type of work, number of children, aura and no-aura migraine, marital status and the MIDAS test groups, which made it impossible to obtain reliable data.

Some of the patients from both groups were post-menopausal and so could not associate menstruation with headaches. For this reason, we excluded such patients from the study and the control group, and for this specific factor the number of females in the compared groups has changed.

The results of the tests revealed a weak connection between the occurrence of headaches and trigger factors such as alcohol 
Table 1. Patients' questionnaire

Please answer the following questions:

First name:

Last name:

Age:

Education:

Primary / Secondary / Higher

Type of work:

Physical / Mental

Marital status:

Number of children:

Do you associate the occurrence of headaches with the following situations? Please circle the correct answer (YES or NO).

After a stressful situation?

After relaxation, holidays or other forms of rest?

After eating products like chocolate, dairy, cocoa, seasonings or citruses?

If yes, please state which products exactly ......

After alcohol consumption?

YES NO

After fasting?

YES NO

After sleep deficiency?

After excessive sleeping?

After workout/fatigue?

After exposure to bright or pulsing light?

After exposure to noise?

After staying at a high altitude (e.g. in the mountains)?

After sudden weather changes?

After medicine intake? If yes, please state which medicines exactly .......

After menstruation?

Do you find any other situations that trigger headaches? If yes, please describe them.

Please answer the following questions:

On how many days in the last 3 months did you miss work or school because of your headaches?

How many days in the last 3 months was your productivity at work or school reduced by half or more because of your headaches?

On how many days in the last 3 months did you not do household work because of your headaches?

How many days in the last 3 months was your productivity in household work reduced by half of more because of your headaches?

On how many days in the last 3 months did you miss family, social or leisure activities because of your headaches?

On how many days in the last 3 months did you have a headache?

On a scale of $0-10$, on average how painful were these headaches? (where $0=$ no pain at all, and $10=$ pain as bad as it can be)

intake, sleep deficiency, excessive sleeping, staying at high altitudes, or medicine intake.

On the other hand, in the following situations: stress exposure, relaxation after stress, intake of dietary products, fasting, workout/fatigue, exposure to bright or pulsing light, high noise level, sudden weather changes and menstruation, the results of the chi-square tests showed statistically significant differences, and the null hypothesis cannot be rejected.

The results are set out in Table 4 .

\section{Discussion}

Our study shows that we can identify headache-triggering factors in migraineurs which have been many times reported as acknowledged migraine trigger factors in previous research studies [9-13, 17]. Kelman retrospectively evaluated 1,750 patients and showed that acute migraine attacks were triggered in around $75 \%$ of patients, with different frequencies, and no triggers were seen in around $25 \%$. The most common triggers included stress $(79.7 \%)$, hormones in women $(65.1 \%)$, fasting (57.3\%), weather (53.2\%), sleep disturbance $(49.8 \%)$, perfume or odour (43.7\%), neck pain (38.4\%), light(s) (38.1\%), alcohol (37.8\%), smoking (35.7\%), sleeping late $(32.0 \%)$, heat $(30.3 \%)$, food (26.9\%), and exercise (22.1\%) [17].

Stress $(82.5 \%)$ was the most frequent migraine headachetriggering factor in our study, which corresponds to the results of other researchers $[9,10,12,17,18]$. Stress is said to trigger headaches in $50-80 \%$ of migraineurs $[9,10,17]$. Moreover, 
Table 2. Demographic data

\begin{tabular}{|c|c|c|c|}
\hline & & $\begin{array}{c}\text { Migraine } \\
\text { group } \\
(n=40)\end{array}$ & $\begin{array}{l}\text { TTH group } \\
(n=40)\end{array}$ \\
\hline \multicolumn{2}{|l|}{ Age range } & $21-66$ & $23-76$ \\
\hline \multirow[t]{2}{*}{ Age (years) } & Mean & 44.62 & 39.5 \\
\hline & $\mathrm{SD}^{1}$ & 10.64 & 15.59 \\
\hline \multirow[t]{2}{*}{ Gender } & Female & $n=40$ & $\mathrm{n}=40$ \\
\hline & Male & $n=0$ & $\mathrm{n}=0$ \\
\hline \multirow[t]{2}{*}{ Type of work } & Physical & 5 & 0 \\
\hline & Mental & 35 & 40 \\
\hline \multirow[t]{3}{*}{ Education } & Primary & 0 & 0 \\
\hline & Secondary & 13 & 15 \\
\hline & Higher & 27 & 25 \\
\hline \multirow[t]{4}{*}{ Marital status } & Single & 12 & 21 \\
\hline & Married & 25 & 14 \\
\hline & Divorced & 1 & 2 \\
\hline & Widowed & 2 & 3 \\
\hline \multirow{4}{*}{$\begin{array}{l}\text { Number of } \\
\text { children }\end{array}$} & 0 & 12 & 22 \\
\hline & 1 & 9 & 10 \\
\hline & 2 & 17 & 7 \\
\hline & $3+$ & 2 & 1 \\
\hline
\end{tabular}

chronic migraine can increase perceived stress and further lower patients' quality of life [12]. Comparing this trigger in other populations, the frequency of stress as a trigger was similar in Spanish and Pakistani populations (46.3\% and 44\%), and slightly higher in Brazilian migraineurs (73\%) [19]. Similar results have been noted in Caucasians ( $87 \%$ recognised stress as a trigger) and African-Americans (84\%) in a questionnaire study focused on identifying ethnic disparities, involving 131 migraine patients [20].

Sudden weather changes (75\%) - our next most frequent trigger, consist of many variables, such as barometric pressure

\begin{tabular}{|c|c|c|c|}
\hline & & \multicolumn{2}{|c|}{$\begin{array}{c}\text { Number of migraine } \\
\text { patients }(n=40)\end{array}$} \\
\hline \multirow{5}{*}{ MIDAS grade } & & $\mathrm{n}$ & $\%$ \\
\hline & 1 & 4 & 10 \\
\hline & $\|$ & 4 & 10 \\
\hline & III & 9 & 22.5 \\
\hline & IV & 22 & 57.5 \\
\hline Migraine without aura & & 34 & 85 \\
\hline Migraine with aura & & 2 & 5 \\
\hline Chronic migraine & & 4 & 10 \\
\hline
\end{tabular}

Table 4. Patients with headaches triggered by the researched factors

\begin{tabular}{|c|c|c|c|c|c|c|}
\hline & \multicolumn{2}{|c|}{$\begin{array}{l}\text { Migraine group } \\
\qquad n=40\end{array}$} & \multicolumn{2}{|c|}{$\begin{array}{l}\text { Control group } \\
\qquad n=40\end{array}$} & \multirow[t]{2}{*}{ P value $^{2}$} & \multirow{2}{*}{$\begin{array}{c}\text { Type of } \\
\text { chi-square test } \\
\text { Pearson }\end{array}$} \\
\hline & $\mathrm{n}$ & $\%$ & $\mathrm{n}$ & $\%$ & & \\
\hline Stress & 33 & 82.5 & 15 & 37.5 & 0.00004 & Chi-square \\
\hline Relaxation after stress & 17 & 42.5 & 5 & 12.5 & 0.003 & \\
\hline Alcohol intake & 20 & 50.0 & 16 & 40.0 & 0.369 & \\
\hline Fasting & 26 & 65.0 & 15 & 37.5 & 0.014 & \\
\hline Sleep deficiency & 25 & 62.5 & 25 & 62.5 & 1.000 & \\
\hline Excessive sleeping & 24 & 60.0 & 17 & 42.5 & 0.117 & \\
\hline Workout/fatigue & 21 & 52.5 & 6 & 15.0 & 0.0004 & \\
\hline Exposure to bright or pulsing light & 25 & 62.5 & 6 & 15.0 & 0.00001 & \\
\hline High noise level & 23 & 57.5 & 12 & 30.0 & 0.013 & \\
\hline Sudden weather changes & 30 & 75.0 & 20 & 50.0 & 0.021 & \\
\hline Medicine intake & 3 & 7.5 & 4 & 10.0 & 1.000 & \\
\hline Menstruation ${ }^{1}$ & $26(n=39)$ & 66.67 & $5(n=26)$ & 19.2 & 0.0002 & \\
\hline Dietary products intake & 15 & 37.5 & 3 & 7.5 & 0.001 & V-square \\
\hline Staying at high altitudes & 11 & 27.5 & 5 & 12.5 & 0.096 & \\
\hline Medicine intake & 3 & 7.5 & 4 & 10.0 & 1.000 & Yates Chi-square \\
\hline
\end{tabular}

'numbers in brackets state the total number of patients in groups due to excluding females after the menopause

${ }^{2} \mathrm{p}$-values in bold are statistically significant $<0.05$ 


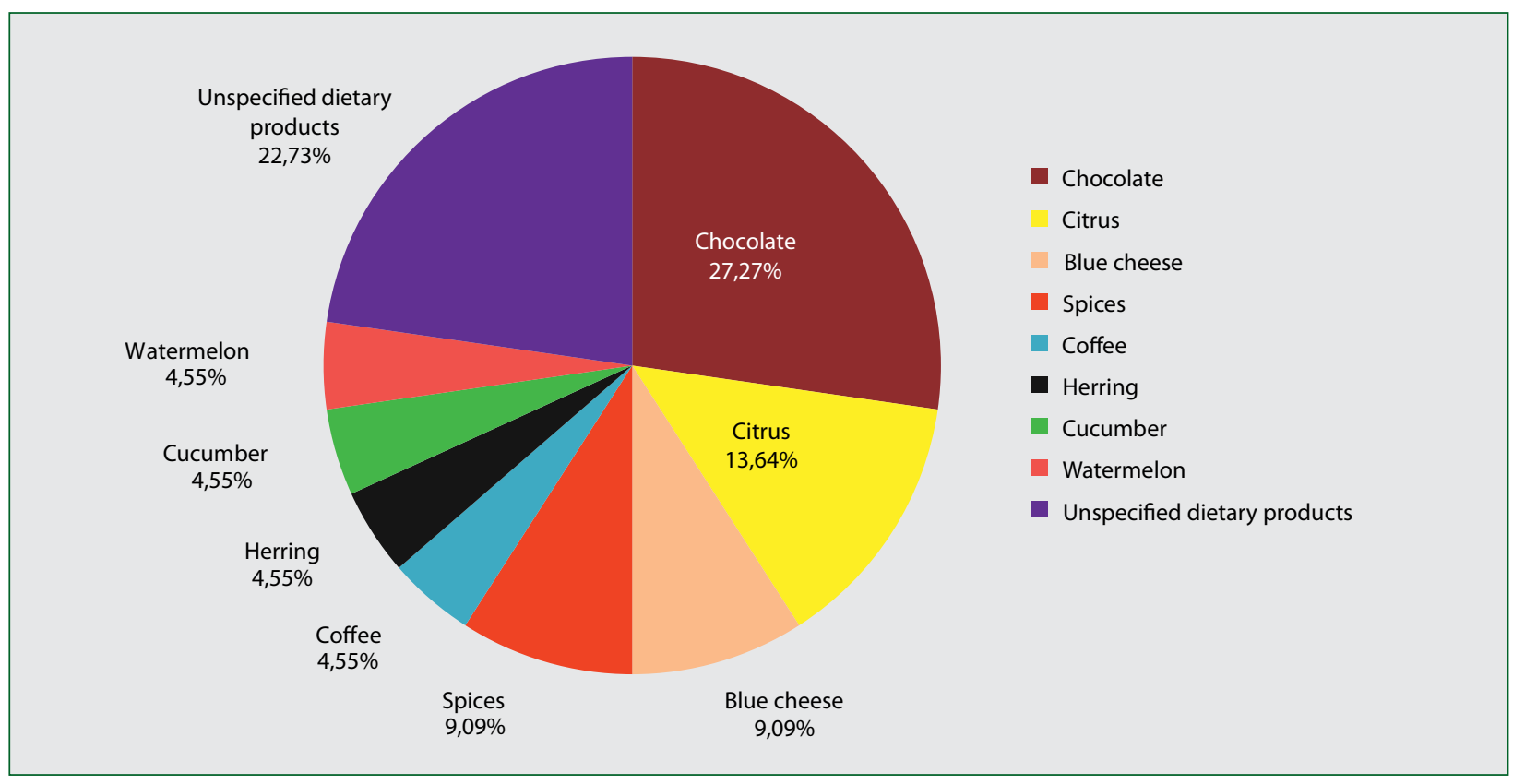

Figure 1. Percentage frequency distribution of dietary products associated with headaches in migraine patients

fluctuations, humidity, temperature, or weather pattern. Prince et al., in a study of 77 patients with migraine, found 39 (50.6\%) to be sensitive to weather changes [21]. Regional weather conditions, like the presence of Chinook winds in Canada, may affect migraine occurrence. Prince et al. wrote: "For the patient group (75) as a whole, headache probability was significantly increased on pre-chinook days, and also on chinook days with high-velocity wind (top quartile of chinook days)" [22]. Other researchers have observed that different air mass types in central North Carolina have an influence on migraine attacks as well: "We found statistically significant differences in ED migraine visits between air mass types. Tropical (i.e. warmer) air masses generally resulted in the highest frequency of $\mathrm{ED}$ visits, while polar (i.e. colder) air masses resulted in the lowest frequency" [23].

Fasting (65\%) is among the best studied and the most reliable natural migraine triggers. Out of all the dietary triggers of migraine attack, fasting is very frequently reported, with percentages ranging from $39 \%$ to $66 \%$ depending on the study [24]. Our questionnaire did not define the duration of fasting nor did it include questions about how much food a patient ate before or during fasting or what kind of food it was. Objective research studies tend to concentrate on specifically defined periods of fasting such as that encouraged by religions. In one study focused on the month of Ramadan, patients identified $9.4 \pm 4.3$ migraine days on average (range 3-20) as compared to $3.7 \pm 2.1$ migraine days on average (range 1-10) during the control month $(\mathrm{p}<0.001)$ [25]. Researchers investigating the phenomenon of Yom Kippur headache reported that in a population including 211 who fasted, $39 \%$ of the fasters developed headaches, compared to only $7 \%$ of non-fasters ( $p$
$<0.000001)$. Also, the number of headache sufferers increased in direct correlation to the duration of the fast [26].

Chocolate was the most common dietary product associated with headaches. Food triggers frequency is similar to many others studies $[27,28]$. Tai et al. in their study involving 319 (46.6\%) Malaysian migraine patients, pointed out that the most common dietary trigger factors were coffee (136 patients, 19.9\%), followed by chocolate (51 patients, 7.5\%) [29]. The comparison of the migraine and the TTH group in Tai's study showed a statistical significance of their findings - chocolate (OR 2.16, 95\% CI 1.06-4.41, $\mathrm{p}=0.035$ ) and coffee (OR 1.73, $95 \%$ CI 1.12-2.68, $\mathrm{p}=0.014)$. Peatfield et al. found that $19.2 \%$ of 490 migraine patients reported sensitivity to chocolate, $18.2 \%$ to cheese, and $11.1 \%$ to citrus fruit [30]. The percentage frequency distribution of different dietary products associated with migraine headaches of our patients is presented in Figure 1.

Our study has some limitations. The study group was relatively small, and all the patients came from a single headache clinic. This study was conducted according to patients' perceived headache triggering factors and observations. The questionnaire did not implement objective scales for said trigger factors. We did not measure noise level, altitudes, or weather parameters such as air pressure or temperature. Furthermore, some patients were on preventive medication, which could have affected the analysed data. All these factors could have an impact on the study's results.

\section{Conclusion}

Although our study presented statistical significance and stated specific trigger factors, which are consistent with studies 
from other countries such as Canada, USA, Turkey, Spain and Korea, we cannot generalise the results to the whole Polish population, due to the study group being too small $[10,13$, $17,29,31]$. In our opinion, this study could prove useful for clinical practice in non-pharmacological preventive treatment in migraine patients, although it should be verified by other studies evaluating the Polish population. Future studies should include larger study groups that would allow the gathering of cross-sectional population data, possibly including additional factors.

Conflict of interest: All authors have no conflict of interest to disclose.

\section{Abbreviations:}

MIDAS - Migraine Disability Assessment Test

TTH - Tension type headache

ICHD-3 - The International Classification of Headache

Disorders $3^{\text {rd }}$ edition

$\mathrm{CDH}-$ Chronic daily headache

BMI - Body mass index

\section{References}

1. Karbowniczek A, Domitrz I. Frequency and clinical characteristics of chronic daily headache in an outpatient clinic setting. Neurol Neurochir Pol. 2011; 45(1): 11-17, indexed in Pubmed: 21384288.

2. Younger DS. Epidemiology of Migraine. Neurol Clin. 2016; 34(4): 849861, doi: 10.1016/j.ncl.2016.06.011, indexed in Pubmed: 27719997.

3. Vetvik K, MacGregor E. Sex differences in the epidemiology, clinical features, and pathophysiology of migraine. The Lancet Neurology. 2017; 16(1): 76-87, doi: 10.1016/s1474-4422(16)30293-9.

4. Stępień A, Prusiński A. Wybrane dane epidemiologiczne wystepowania migreny w Polsce, Ból : kwartalnik Polskiego Towarzystwa Badania Bólu. 2003, 1640-324X. T. 4, nr 3 s. : 9-11.

5. Chu MK, Kim DW, Kim BK, et al. Gender-specific influence of socioeconomic status on the prevalence of migraine and tension-type headache: the results from the Korean Headache Survey. J Headache Pain. 2013; 14: 82, doi: 10.1186/1129-2377-14-82, indexed in Pubmed: 24093215.

6. Stewart WF, Roy J, Lipton RB. Migraine prevalence, socioeconomic status, and social causation. Neurology. 2013; 81(11): 948-955, doi: 10.1212/WNL.0b013e3182a43b32, indexed in Pubmed: 23990405.

7. Kim SY, Park SP. The role of headache chronicity among predictors contributing to quality of life in patients with migraine: a hospitalbased study. J Headache Pain. 2014; 15: 68, doi: 10.1186/11292377-15-68, indexed in Pubmed: 25278151.

8. Bera SC, Khandelwal SK, Sood M, et al. A comparative study of psychiatric comorbidity, quality of life and disability in patients with migraine and tension type headache. Neurol India. 2014; 62(5): 516-520, doi: 10.4103/0028-3886.144445, indexed in Pubmed: 25387621.

9. Peroutka SJ. What turns on a migraine? A systematic review of migraine precipitating factors. Curr Pain Headache Rep. 2014; 18(10): 454, doi: 10.1007/s11916-014-0454-z, indexed in Pubmed: 25160711.

10. Mollaoğlu M. Trigger factors in migraine patients. J Health Psychol. 2013; 18(7): 984-994, doi: 10.1177/1359105312446773, indexed in Pubmed: 23104993.
11. Fernández-de-Las-Peñas C, Fernández-Muñoz JJ, Palacios-Ceña M, et al. Sleep disturbances in tension-type headache and migraine. Ther Adv Neurol Disord. 2018; 11: 1756285617745444, doi: 10.1177/1756285617745444, indexed in Pubmed: 29399051.

12. Moon HJ, Seo JG, Park SP. Perceived stress in patients with migraine: a case-control study. J Headache Pain. 2017; 18(1): 73, doi: 10.1186/ s10194-017-0780-8, indexed in Pubmed: 28733942.

13. Zaeem Z, Zhou L, Dilli E. Headaches: a Review of the Role of Dietary Factors. Curr Neurol Neurosci Rep. 2016; 16(11): 101, doi: 10.1007/ s11910-016-0702-1, indexed in Pubmed: 27714637.

14. Headache Classification Committee of the International Headache Society (IHS) The International Classification of Headache Disorders, 3rd edition. Cephalalgia. 2018; 38(1): 1-211, doi: 10.1177/0333102417738202, indexed in Pubmed: 29368949.

15. Chorążka $K$, Janoska M, Swić P, Domitrz I, Body mass index and serum lipid levels in effect on the incidence and course of migraine, Neurol Neurochir Pol. 2013; 47(6): 572-6.

16. Stewart WF, Lipton RB, Kolodner K, et al. Reliability of the migraine disability assessment score in a population-based sample of headache sufferers. Cephalalgia. 1999; 19(2): 107-14; discussion 74, doi: 10.1046/j.1468-2982.1999.019002107.x, indexed in Pubmed: 10214536.

17. Kelman L. The triggers or precipitants of the acute migraine attack. Cephalalgia. 2007; 27(5): 394-402, doi: 10.1111/j.14682982.2007.01303.x, indexed in Pubmed: 17403039.

18. Yalinay Dikmen P, Yavuz BG, Aydinlar El. The relationships between migraine, depression, anxiety, stress, and sleep disturbances. Acta Neurol Belg. 2015; 115(2): 117-122, doi: 10.1007/s13760-0140312-0, indexed in Pubmed: 24889393.

19. Carod-Artal FJ, Ezpeleta D, Martín-Barriga ML, et al. Triggers, symptoms, and treatment in two populations of migraneurs in Brazil and Spain. A cross-cultural study. J Neurol Sci. 2011; 304(1-2): 25-28, doi: 10.1016/j.jns.2011.02.027, indexed in Pubmed: 21402387.

20. Nicholson RA, Rooney M, Vo K, et al. Migraine care among different ethnicities: do disparities exist? Headache. 2006; 46(5): 754-765, doi: 10.1111/j.1526-4610.2006.00453.x, indexed in Pubmed: 16643578.

21. Prince PB, Rapoport AM, Sheftell FD, et al. The effect of weather on headache. Headache. 2004; 44(6): 596-602, doi: 10.1111/j.15264610.2004.446008.x, indexed in Pubmed: 15186304.

22. Cooke L, Rose MS, Becker WJ. Chinook winds and migraine headache. Neurology. 2000; 54(2): 302-307, doi: 10.1212/wnl.54.2.302, indexed in Pubmed: 10668687.

23. Elcik C, Fuhrmann CM, Mercer AE, et al. Relationship between air mass type and emergency department visits for migraine headache across the Triangle region of North Carolina. Int J Biometeorol. 2017; 61(12): 2245-2254, doi: 10.1007/s00484-017-1432-z, indexed in Pubmed: 28900742.

24. AA S, CAC d, RP SN. Headaches and Food Abstinence: A Review. Journal of Clinical Case Studies. 2018; 3(2), doi: 10.16966/24714925.163.

25. Abu-Salameh I, Plakht Y, Ifergane G. Migraine exacerbation during Ramadan fasting. J Headache Pain. 2010; 11(6): 513-517, doi: 10.1007/s10194-010-0242-z, indexed in Pubmed: 20652352.

26. Mosek A, Korczyn AD. Yom Kippur headache. Neurology. 1995; 45(11): 1953-1955, doi: 10.1212/wnl.45.11.1953, indexed in Pubmed: 7501139.

27. Fukui PT, Gonçalves TR, Strabelli CG, et al. Trigger factors in migraine patients. Arq Neuropsiquiatr. 2008; 66(3A): 494-499, 
doi: 10.1590/s0004-282x2008000400011, indexed in Pubmed: 18813707.

28. Wöber C, Wöber-Bingöl C. Triggers of migraine and tension-type headache. Handb Clin Neurol. 2010; 97: 161-172, doi: 10.1016/S00729752(10)97012-7, indexed in Pubmed: 20816418.

29. Tai MLS, Yap JF, Goh CB. Dietary trigger factors of migraine and tensiontype headache in a South East Asian country. J Pain Res. 2018; 11: 12551261, doi: 10.2147/JPR.S158151, indexed in Pubmed: 29988763.
30. Peatfield RC, Glover V, Littlewood JT, et al. The prevalence of diet-induced migraine. Cephalalgia. 1984; 4(3): 179-183, doi: 10.1046/j.1468-2982.1984.0403179.x, indexed in Pubmed: 6498931.

31. Park JW, Chu MK, Kim JM, et al. Analysis of Trigger Factors in Episodic Migraineurs Using a Smartphone Headache Diary Applications. PLoS One. 2016; 11(2): e0149577, doi: 10.1371/journal.pone.0149577, indexed in Pubmed: 26901341. 